\title{
Effect of NHS reforms on general practitioners' referral patterns
}

\author{
Angela Coulter, Jean Bradlow
}

\author{
Abstract \\ Objective-To compare outpatient referral \\ patterns in fundholding and non-fundholding prac- \\ tices before and after the implementation of the \\ NHS reforms in April 1991.
}

Design-Prospective collection of data on general practitioners' referrals to specialist outpatient clinics between June 1990 and March 1992 and detailed comparison of two time periods: October 1990 to March 1991 (phase 1) and October 1991 to March 1992 (phase 2).

Setting-10 fundholding practices and six nonfundholding practices in the Oxford region.

Subjects-Patients referred to consultant outpatient clinics.

Results-After implementation of the NHS reforms there was no change in the proportion of referrals from the two groups of practices which crossed district boundaries. Both groups of practices increased their referral rates in phase 2 of the study, the fundholders from $107 \cdot 3$ per 1000 patients per annum (95\% confidence interval 106 to 109$)$ to $111.4(110$ to 113$)$ and the non-fundholders from 95.0 (93 to 97 ) to 112.0 (110 to 114$)$. In phase 2 there was no difference in overall standardised referral rates between fundholders and non-fundholders. Just over $20 \%$ of referrals went to private clinics in phase 1. By phase 2 this proportion had reduced by $2 \cdot 2 \%$ $(1.0 \%$ to $3.4 \%)$ among the fundholders and by $2.7 \%$ $(1 \cdot 2 \%$ to $4 \cdot 2 \%)$ among the non-fundholders.

Conclusions-Referral patterns among fundholders and non-fundholders were strikingly similar after the implementation of the NHS reforms. There was no evidence that fundholding was encouraging a shift from specialist to general practice care or that budgetary pressures were affecting general practitioners' referral behaviour.

\section{Introduction}

The general practice fundholding scheme, which was introduced as part of the package of organisational reforms to the NHS in April 1991, ${ }^{1}$ has attracted a great deal of comment. ${ }^{2-4}$ This voluntary scheme, which gives general practitioners control over budgets to cover prescriptions, specialist outpatient consultations, and elective surgical procedures for their patients, has been embraced with enthusiasm by some general practitioners, but others have been concerned that it could encourage the development of a "two tier" service, in which the advantages gained by fundholders for their patients are achieved at the expense of patients in other practices. Proper evaluation of the scheme requires more than the anecdotal accounts published so far if the true effects are to be monitored and the policy lessons learnt. We report the first results from a study designed to evaluate the effects of the NHS reforms in general practices and hospitals in the Oxford region.

Our study has collected data from 10 first wave fundholding practices and seven non-fundholding practices to measure their use of hospital care (in-. patient and outpatient), the speed and nature of the $\overrightarrow{\vec{\omega}}$ hospitals' response to requests from the practices, $\stackrel{\circ}{\circ}$ prescribing patterns and costs, and any innovations or $\frac{0}{3}$ changes introduced in practice based facilities, as well as monitoring the views and experience of general $\bigcirc$ practitioners, hospital consultants, and patients. A comparison group of non-fundholding practices was essential to disentangle the effects of budget holding from any wider effects of the NHS reforms.

This paper is concerned with the effects of the $\mathrm{O}$ reforms on general practitioners' referrals to specialist outpatient clinics. There were several reasons for $\vec{\omega}$ anticipating a change in referral patterns after April ${ }_{\mathbb{D}}^{T}$ 1991. The opportunity to maintain their freedom of $\frac{O}{C}$ referral was one of the commonest reasons given by general practitioners for joining the fundholding scheme. ${ }^{2}$ Many general practitioners feared that non- $\vec{\theta}$ fundholders would be forced to restrict their referrals $\omega$ to hospitals with which their district health authority had contracts, which might inhibit their freedom to refer outside the boundaries of their local district. We were therefore interested to see whether there was any evidence that these fears had been justified.

Another attraction of the scheme is the flexibility it gives to general practitioners to make budgetary음 savings in certain aspects of their clinical practice which can then be reinvested in other aspects of patient care. Evidence of wide variations in outpatient referral rates is indicative of a lack of consensus about the appropriateness of specialist referral in many situations. ${ }^{5}$ It seemed possible that outpatient referrals $\frac{\text { 을 }}{3}$ might provide scope for savings if fundholding general: practitioners were to refrain from referring patients in cases where they were ambivalent about the necessity for specialist intervention.

Another reason for expecting fundholders' referraln rates to fall after April 1991 had to do with the way $>$ in which their budgets were set. ${ }^{6}$ When the scheme음 was introduced there was speculation about whether those intending to become fundholders would increase $N$ referral rates in the preparatory year to ensure that ${ }^{\omega}$ their budgets, which were based on historical activity, were large enough to permit savings in subsequento years. It therefore seemed possible that referral rates would be higher among fundholders than among control practices in the year before the introduction of budgets, but that fundholders' NHS referral rates would then fall.

Referrals from fundholding practices to private $\cong$ clinics, on the other hand, might be expected to increase as fundholders would have an incentive too encourage privately insured patients to claim from? their insurance companies to avoid incurring a chargeô. against the practice budget. Fundholders were also? free to purchase care for NHS patients in the private sector, so we were interested to see the extent to which this option was being taken up.

Three main questions were therefore addressed: did 
non-fundholders reduce their rate of referral outside the boundaries of their local district health authority? did first wave fundholders reduce their referral rates to NHS outpatient clinics and, if so, which specialties and which patients were affected? did the proportion of patients referred by fundholders to private clinics increase and how many private referrals were paid for out of the NHS budget?

\section{Methods}

Early in 1990 we developed and piloted a referral form, which was used to collect data in the preparatory year by all practices in the Oxford Regional Health Authority that had expressed an interest in fundholding. ${ }^{7}$ We also wrote to all those practices within the region with more than 8000 registered patients that did not intend to enter the fundholding scheme inviting them to act as controls in the study. Six practices agreed to participate and one additional, smaller practice (6119 patients) was also recruited as a control. One of the non-fundholding control practices was excluded from the analysis because it did not collect referral data for a significant part of the study. Ten of the 25 practices in the Oxford Regional Health Authority which entered the first wave of the fundholding scheme were asked to continue collecting referral data for a further year. These 10 practices were selected to match the controls as far as possible in terms of practice size, location, and main provider unit.

Each time a referral was made details of the referring general practitioner; the patient's sex and date of birth; the consultant, specialty, and hospital to - which the referral was made; the symptoms or diagnosis; and the main reason for making the referral were recorded. Referrals to consultant clinics were included regardless of location, so patients seen in general practice based consultant clinics were counted as referrals. Liaison was established with one or two members of the practice staff, usually a general practitioner and a member of the administrative staff, and systems were established to ensure accuracy of information. This close liaison was maintained with all practices throughout the study. Aggregated referral data were regularly fed back to the practices for checking against figures collected internally. Any discrepancies between the two data sources were investigated and errors eliminated.

The aim was to monitor only those outpatient referrals which incurred a charge against fundholders' budgets and the corresponding referrals in the control practices. Hence referrals to the following clinics were excluded from the analysis: palliative care, oncology, renal units, radiotherapy, clinical genetics, obstetrics, sexually transmitted disease clinics, child guidance clinics, all paramedical referrals, accident and emergency and emergency inpatient referrals, consultant cross referrals and tertiary referrals, all self referrals (by patients themselves), and referrals made by district health authority staff-for example, health visitors. Although included in the fundholding scheme, referrals to radiology, pathology, physiotherapy, speech therapy, and occupational therapy were also

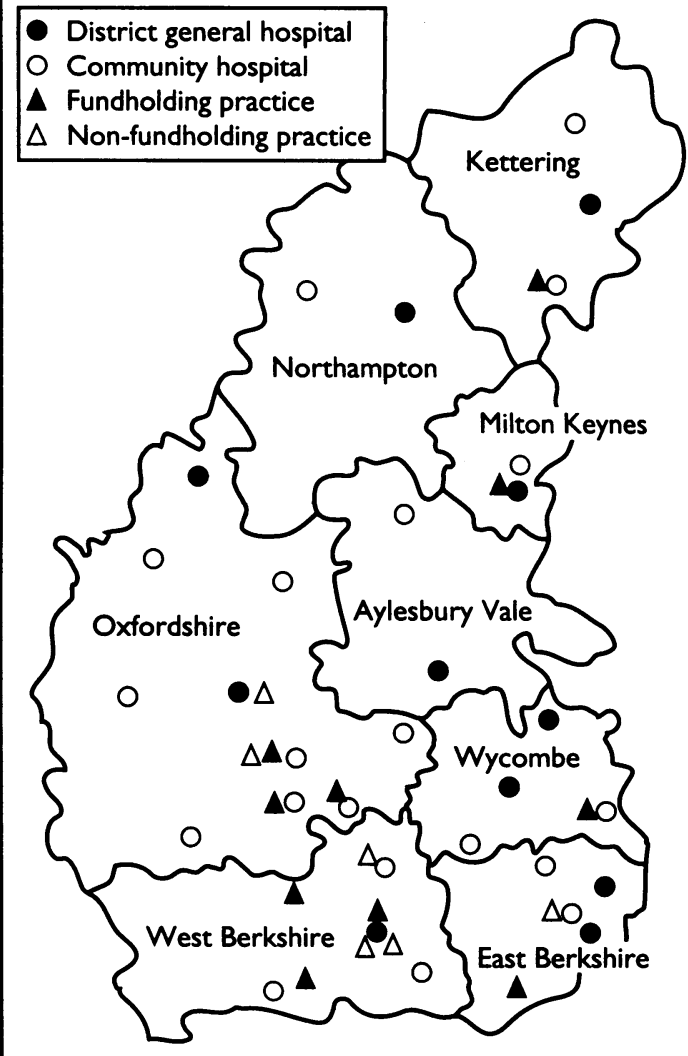

Location of practices and provider units

excluded from this analysis, which focused on referrals to consultants' outpatient clinics.

Data collection took place between June 1990 and March 1992. Detailed analysis focused on two six month periods-phase 1 (the preparatory year) from 1 October 1990 to 31 March 1991, and phase 2 (the first year after the introduction of the reforms in April 1991) from 1 October 1991 to 31 March 1992. All 10 fundholding practices and three of the six non-fundholding practices contributed data for the whole of these two periods. Of the remaining three practices, one contributed for all but one of the 12 months' data collection period, one supplied data for 10 out of 12 months, and one supplied data for eight months only. These data were used to calculate annual referral rates using the practice populations as the denominator. Population figures were obtained directly from the practices' computer systems. Annual referral rates for each practice were standardised for age and sex by the direct method using the total study population as the standard. Proportions were compared by $\chi^{2}$ test. Confidence intervals for proportions and standardised rates were derived by using the software package CIA.$^{8}$

\section{Results}

The two groups of study practices were reasonably well matched (table I). The fundholding practices in the study were also very comparable to the remaining

TABLE I-Number and characteristics of study practices and other first wave fundholding practices in Oxford Regional Health Authority

\begin{tabular}{lccc}
\hline & $\begin{array}{c}\text { Fundholding practices } \\
\text { in study }\end{array}$ & $\begin{array}{c}\text { Other first wave } \\
\text { fundholding practices }\end{array}$ & $\begin{array}{c}\text { Non-fundholding } \\
\text { control practices }\end{array}$ \\
\hline No of practices & 10 & 15 & 6 \\
No of general practitioners & 65 & 92 & 42 \\
Mean No of partners per practice & $6 \cdot 5$ & 6.1 & $\mathbf{7}$ \\
Total practice population & 127984 & 195465 & 88219 \\
Mean list size per practice (range) & $12798(9017$ to 23689) & $13031(9171$ to 19068$)$ & $14703(6119$ to 23 2354) \\
No (\%) of patients attracting deprivation allowance & $7(70 \cdot 0)$ & $3518(1 \cdot 8)$ & 0 \\
No (\%) of training practices & $10(100 \cdot 0)$ & $11(73 \cdot 3)$ & $5(83 \cdot 3)$ \\
No (\%) of practices using computers & $10(100 \cdot 0)$ & $15(100 \cdot 0)$ & $5(83.3)$ \\
No (\%) of practices employing practice managers & & $15(100 \cdot 0)$ & $6(100 \cdot 0)$ \\
\hline
\end{tabular}


fundholding practices in the region on the available indicators. The study fundholders were based in six of the eight district health authorities in the Oxford region whereas the controls were located in only three districts (figure). The Oxford Regional Health Authority is well served by community hospitals, where outpatient clinics are held in addition to those in general hospitals, so none of the participating practices was far from a provider unit. All study practices were in relatively prosperous areas: none was in receipt of a deprivation allowance. Five of the 10 fundholding practices and three of the six control practices had a proportion of their patients in rural areas. The proportion of patients classified as rural was $12.6 \%$ in the fundholding group and $9.0 \%$ among the controls. During the two study periods these practices kept records of 28371 referrals.

The extent to which the organisational changes affected referral patterns was first investigated by looking at the proportion of referrals which crossed district boundaries before and after the implementation of the reforms in the two groups of practices (table II). The fundholding practices had higher rates of cross boundary referrals than the control practices before the reforms; however, there was little evidence of change between the two study periods in either group. Only in general surgery and paediatrics was there a significant increase in out of district referrals among fundholders $\left(\chi^{2}=18.82, p<0.001 ; \chi^{2}=7.05, p<0.01\right)$. The proportion of fundholders' referrals to out of district psychiatric clinics decreased $\left(\chi^{2}=9.37, \mathrm{p}<0.005\right)$. There were no significant differences in out of district referrals to individual specialties among the nonfundholding practices.

Contrary to expectations, fundholders' NHS referral rates showed a small but significant increase from the first phase to the second phase of the study (table III). The rates in control practices were lower than those of the fundholders in the first phase, but by phase 2 the non-fundholders had increased their referral rates to

TABLE II-Percentages of NHS outpatient referrals going outside district health authorities in which practices were located

\begin{tabular}{lccccc}
\hline & \multicolumn{2}{c}{ Fundholding practices } & & \multicolumn{2}{c}{ Controls } \\
\cline { 2 - 3 } \cline { 5 - 6 } \cline { 5 - 6 } Specialty & $\begin{array}{c}\text { Phase 1 } \\
(\mathrm{n}=8666)\end{array}$ & $\begin{array}{c}\text { Phase 2 } \\
(\mathrm{n}=8885)\end{array}$ & & $\begin{array}{c}\text { Phase 1 } \\
(\mathrm{n}=4550)\end{array}$ & $\begin{array}{c}\text { Phase 2 } \\
(\mathrm{n}=6270)\end{array}$ \\
\hline General surgery & 5.8 & 10.2 & & 1.8 & 1.0 \\
General medicine & 10.3 & 10.2 & & 3.5 & 2.5 \\
Gynaecology & 9.3 & 6.1 & & 3.0 & 3.8 \\
Orthopaedic surgery & 4.9 & 7.2 & & 2.8 & 1.9 \\
Ear, nose, throat & 7.1 & 8.1 & & 0.5 & 0.8 \\
Dermatology & 5.7 & 4.6 & 2.1 & 0.9 \\
Ophthalmology & 6.6 & 7.1 & 1.1 & 2.5 \\
Psychiatry & 21.6 & 12.8 & & 0.5 & 1.1 \\
Rheumatology & 4.6 & 8.1 & 6.3 & 1.7 \\
Paediatrics & 1.7 & 6.5 & 2.2 & 1.1 \\
Plastic surgery & 7.8 & 15.5 & 10.5 & 7.5 \\
\hline All specialties & 7.7 & 8.4 & 2.3 & 1.9 \\
\hline
\end{tabular}

TABLE III-Standardised referral rates (NHS only) per 1000 population per year from fundholding practices and controls by specialty

\begin{tabular}{|c|c|c|c|c|}
\hline \multirow[b]{2}{*}{ Specialty } & \multicolumn{2}{|c|}{ Fundholding practices } & \multicolumn{2}{|c|}{ Controls } \\
\hline & $\begin{array}{c}\text { Phase 1 } \\
(n=8666)\end{array}$ & $\begin{array}{c}\text { Phase 2 } \\
(n=8885)\end{array}$ & $\begin{array}{c}\text { Phase 1 } \\
(n=4550)\end{array}$ & $\begin{array}{c}\text { Phase 2 } \\
(n=6270)\end{array}$ \\
\hline General surgery & $21 \cdot 0$ & $22 \cdot 8$ & $18 \cdot 2$ & $21 \cdot 3$ \\
\hline General medicine & $18 \cdot 4$ & $16 \cdot 6$ & 15.5 & 19.0 \\
\hline Gynaecology & $14 \cdot 7$ & $14 \cdot 7$ & $12 \cdot 1$ & $11 \cdot 8$ \\
\hline Orthopaedic surgery & $10 \cdot 4$ & $12 \cdot 0$ & $10 \cdot 2$ & 11.9 \\
\hline Ear, nose, throat & 11.9 & $12 \cdot 6$ & 11.5 & $11 \cdot 7$ \\
\hline Dermatology & 7.9 & $8 \cdot 4$ & $7 \cdot 8$ & 9.9 \\
\hline Ophthalmology & $8 \cdot 4$ & $8 \cdot 7$ & $7 \cdot 3$ & $8 \cdot 1$ \\
\hline Psychiatry & $4 \cdot 7$ & 5.8 & $5 \cdot 0$ & 5.9 \\
\hline Rheumatology & $3 \cdot 7$ & $3 \cdot 2$ & $2 \cdot 6$ & 3.8 \\
\hline Paediatrics & $3 \cdot 4$ & $4 \cdot 1$ & $2 \cdot 7$ & $4 \cdot 2$ \\
\hline Plastic surgery & 1.6 & 1.6 & $1 \cdot 2$ & $2 \cdot 1$ \\
\hline $\begin{array}{l}\text { All specialties } \\
\text { (95\% confidence } \\
\text { interval) }\end{array}$ & $107 \cdot 3(106$ to 109$)$ & $111.4(110$ to 113$)$ & $95.0(92.9$ to 97.0$)$ & $112.0(110$ to 114$)$ \\
\hline
\end{tabular}

TABLE IV-Age specific referral rates (NHS only) to all specialties combined, expressed as annual rates per 1000 population in each agesex group

\begin{tabular}{|c|c|c|c|c|}
\hline \multirow[b]{2}{*}{ Age group (years) } & \multicolumn{2}{|c|}{ Fundholding practices } & \multicolumn{2}{|c|}{ Controls } \\
\hline & Phase 1 & Phase 2 & Phase 1 & Phase 2 \\
\hline $\begin{array}{l}0-4 \\
5-14 \\
15-24 \\
25-34 \\
35-44 \\
45-54 \\
55-64 \\
65-74 \\
\geqslant 75\end{array}$ & $\begin{array}{r}110 \cdot 2 \\
60.4 \\
55.5 \\
76.1 \\
65.9 \\
82.6 \\
126.9 \\
167.4 \\
192.1\end{array}$ & $\begin{array}{r}\text { Males } \\
126 \cdot 1 \\
72 \cdot 0 \\
59 \cdot 5 \\
72 \cdot 2 \\
80 \cdot 4 \\
88.0 \\
141 \cdot 3 \\
171 \cdot 4 \\
207 \cdot 4\end{array}$ & $\begin{array}{r}114 \cdot 2 \\
63.0 \\
45 \cdot 1 \\
54.0 \\
55 \cdot 0 \\
84 \cdot 2 \\
109 \cdot 6 \\
172.9 \\
215 \cdot 6\end{array}$ & $\begin{array}{r}124 \cdot 1 \\
70.9 \\
58 \cdot 0 \\
67 \cdot 8 \\
72 \cdot 8 \\
89 \cdot 3 \\
127 \cdot 2 \\
190 \cdot 6 \\
269 \cdot 0\end{array}$ \\
\hline All ages & $86 \cdot 5$ & $94 \cdot 4$ & $78 \cdot 2$ & $92 \cdot 4$ \\
\hline $\begin{array}{c}0-4 \\
5-14 \\
15-24 \\
25-34 \\
35-44 \\
45-54 \\
55-64 \\
65-74 \\
\geqslant 75\end{array}$ & $\begin{array}{r}79.9 \\
62.0 \\
98.3 \\
139.7 \\
141.2 \\
159.7 \\
146.5 \\
178.2 \\
184.0\end{array}$ & $\begin{array}{r}\text { males } \\
91.9 \\
59.6 \\
93.1 \\
141.2 \\
156.3 \\
148.7 \\
145.7 \\
172.4 \\
188.0\end{array}$ & $\begin{array}{r}78 \cdot 8 \\
49 \cdot 8 \\
83 \cdot 2 \\
107.7 \\
117.5 \\
136.6 \\
152.9 \\
144.8 \\
175.7\end{array}$ & $\begin{array}{r}83.6 \\
68.7 \\
93.3 \\
134.1 \\
141.7 \\
152.2 \\
149.4 \\
194.8 \\
211.3\end{array}$ \\
\hline All ages & $127 \cdot 8$ & 128.9 & $111 \cdot 1$ & 130.5 \\
\hline
\end{tabular}

TABLE V-Standardised referral rates (NHS and private) per 1000 population per annum in individual practices

\begin{tabular}{|c|c|c|c|c|}
\hline \multirow[b]{2}{*}{ Practice No } & \multicolumn{2}{|c|}{ NHS } & \multicolumn{2}{|c|}{ Private } \\
\hline & Phase 1 & Phase 2 & Phase 1 & Phase 2 \\
\hline \multicolumn{5}{|c|}{ Fundholding practices } \\
\hline 1 & $89 \cdot 0$ & $100 \cdot 1$ & $85 \cdot 5$ & $89 \cdot 5$ \\
\hline 2 & $92 \cdot 1$ & 93.9 & 13.6 & $10 \cdot 6$ \\
\hline 3 & 92.9 & $102 \cdot 7$ & $50 \cdot 2$ & $45 \cdot 1$ \\
\hline 4 & $99 \cdot 1$ & $108 \cdot 3$ & 15.9 & $13 \cdot 4$ \\
\hline 5 & $104 \cdot 6$ & $100 \cdot 5$ & $31 \cdot 3$ & $30 \cdot 7$ \\
\hline 6 & $109 \cdot 2$ & $96 \cdot 1$ & $11 \cdot 3$ & $6 \cdot 2$ \\
\hline 7 & $110 \cdot 8$ & 115.9 & $15 \cdot 2$ & $15 \cdot 8$ \\
\hline 8 & $111 \cdot 4$ & $113 \cdot 1$ & $22 \cdot 2$ & $15 \cdot 5$ \\
\hline 9 & $142 \cdot 5$ & $158 \cdot 6$ & $25 \cdot 4$ & $20 \cdot 9$ \\
\hline 10 & $145 \cdot 0$ & 131.9 & $23 \cdot 6$ & 18.5 \\
\hline \multicolumn{5}{|c|}{ Controls } \\
\hline 1 & $90 \cdot 5$ & 132.9 & $20 \cdot 0$ & 21.5 \\
\hline 2 & $91 \cdot 4$ & $99 \cdot 8$ & 31.6 & $27 \cdot 4$ \\
\hline 3 & $93 \cdot 7$ & $160 \cdot 2$ & $27 \cdot 4$ & $29 \cdot 2$ \\
\hline 4 & $98 \cdot 0$ & $116 \cdot 3$ & $36 \cdot 0$ & $46 \cdot 1$ \\
\hline 5 & $99 \cdot 0$ & $118 \cdot 1$ & $37 \cdot 4$ & $35 \cdot 7$ \\
\hline 6 & $111 \cdot 7$ & $106 \cdot 2$ & $13 \cdot 7$ & $12 \cdot 7$ \\
\hline
\end{tabular}

the same level as the fundholders. The distribution of referrals to each individual specialty was very similar in the two groups of practices. Interestingly, fundholders' referrals to clinics in general surgery and orthopaedic surgery increased whereas they decreased in general medicine and remained the same in most other specialties. Fundholders' referral rates to general surgery increased from $21 \cdot 0(95 \%$ confidence interval $20 \cdot 2$ to $21.8)$ to $22.9(22.0$ to 23.7$)$ and to orthopaedic surgery from $10 \cdot 4(9 \cdot 8$ to $10 \cdot 9)$ to $12 \cdot 0(11 \cdot 4$ to $12 \cdot 6)$.

The increased likelihood of referral occurred among both male and female patients in the two groups of practices, although female patients between the ages of 5-24 and 45-74 in fundholding practices were slightly less likely to be referred in the second phase of the study than in the first (table IV). The age and sex specific referral rates from the two groups of practices were very similar in phase 2 of the study.

Seven of the 10 fundholding practices and five of the six control practices had increased their NHS referral rates by the second phase of the study (table V). It is worth noting that changes among the two highest referring practices in phase 1 , fundholding practices 9 and 10, went in opposite directions; practice 9 increased its rate whereas practice 10 decreased.

Referrals to private clinics decreased among the fundholders, also contrary to expectations. Standardised private patient referral rates from fundholding practices decreased from $27 \cdot 2$ in phase $1(95 \%$ confi- 
dence interval $26 \cdot 3$ to $28 \cdot 2)$ to $24.6(23.8$ to $25 \cdot 5)$ in phase 2 . This represented a reduction of $2 \cdot 2 \%(95 \%$ confidence interval $1.0 \%$ to $3.4 \% ; \chi^{2}=13.32, p<0.001$ ) in the proportion of total referrals which went to private clinics. Private referral rates among nonfundholders, however, stayed at the same level in the two phases of the study: $27 \cdot 8$ in phase $1(26 \cdot 7$ to $29 \cdot 0)$ and 27.8 in phase $2(26.7$ to 28.9$)$, although as NHS referrals increased in the second phase this represented a reduction of $2 \cdot 7 \%\left(1 \cdot 2 \%\right.$ to $\left.4 \cdot 2 \% ; \chi^{2}=12 \cdot 89, \mathrm{p}<0.001\right)$ in the proportion of total referrals. Only two of the fundholding practices ( 1 and 7 ) had increased their private referral rates in phase 2 as compared with phase 1 .

The variation between the practices in NHS referral rates was relatively low, ranging from 89.0 per 1000 in a fundholding practice in phase 1 to 160.2 in a control practice in phase 2 . Private referral rates were much more variable, the lowest being 6.2 per 1000 and the highest $89 \cdot 5$, a 14 -fold difference in rates. Nearly half of all referrals from the latter practice (a fundholder) went to private clinics, but this proportion remained unchanged between the two phases of the study. The similarities between the two groups of practices in the proportion going to private clinics in each individual specialty (table VI) were much more striking than the differences.

TABLE VI-Percentages of total outpatient referrals to each specialty which were private*

\begin{tabular}{lccccc}
\hline & \multicolumn{2}{c}{ Fundholding practices } & & \multicolumn{2}{c}{ Controls } \\
\cline { 2 - 3 } \cline { 5 - 6 } \cline { 5 - 6 } Specialty & $\begin{array}{c}\text { Phase 1 } \\
(\mathrm{n}=8666)\end{array}$ & $\begin{array}{c}\text { Phase 2 } \\
(\mathrm{n}=8885)\end{array}$ & & $\begin{array}{c}\text { Phase 1 } \\
(\mathrm{n}=4550)\end{array}$ & $\begin{array}{c}\text { Phase 2 } \\
(\mathrm{n}=6270)\end{array}$ \\
\hline General surgery & 21.6 & 19.0 & & 21.4 & 20.4 \\
General medicine & 17.0 & 19.4 & & 21.5 & 19.5 \\
Gynaecology & 18.5 & 16.4 & & 22.5 & 17.8 \\
Orthopaedic surgery & 29.5 & 22.0 & & 29.2 & 28.6 \\
Ear, nose, throat & 20.5 & 18.4 & & 24.5 & 22.4 \\
Dermatology & 21.9 & 21.0 & & 26.8 & 18.9 \\
Ophthalmology & 18.4 & 14.8 & & 16.2 & 17.5 \\
Psychiatry & 9.3 & 7.6 & & 9.6 & 6.3 \\
Rheumatology & 22.8 & 21.0 & & 20.6 & 13.6 \\
Paediatrics & 10.8 & 11.0 & & 17.8 & 11.5 \\
Plastic surgery & 34.8 & 29.5 & & 39.4 & 30.4 \\
\hline All specialties & 20.4 & 18.2 & & 22.6 & 19.9 \\
\hline
\end{tabular}

^Excluding NHS referrals to private clinics.

The number of NHS patients referred from fundholding practices to private clinics (paid for out of the fundholder's budget) in phase 2 was small: of the 59 referrals that fell into this category, most were for vasectomy or female sterilisation. Before 1991 vasectomy was not normally available within the NHS. Three of the fundholding practices arranged private contracts for this procedure paid out of their practice budgets as a means of improving the services available to their patients.

\section{Discussion}

REFERRAL PATTERNS BEFORE AND AFTER REFORMS

These results contradict our prior expectations about the effects of the NHS reforms on referral patterns. Indeed, the overriding impression is that referral patterns remained strikingly similar among both fundholders and non-fundholders after the implementation of the organisational changes. We do not know how far these findings are generalisable at a national level, but we are reasonably confident that the study practices were representative of the totality of fundholding practices in the Oxford region and that the fundholding and control practices were fairly well matched on those variables, such as distance from provider units, which might have affected referral patterns.

Our findings provide no evidence that non-fund- holders were more restricted in their freedom to refer across district boundaries than they had been hitherto. We did not look specifically at extracontractual referrals and the extent to which payment for these was refused by purchasing authorities, but there is no evidence from our results that the contracting system affected out of district referrals from this group of practices to any great extent. The fact that those practices which became fundholders had a history of referring patients across district boundaries to a greater extent than the controls in our study may provide an indication of their motivation for joining the scheme. In other words, they may have seen it as a means of safeguarding their referral patterns, which might have been threatened had they been forced to restrict themselves to contracts made by district health authority purchasers. For the control practices, w'.h their low rate of cross boundary referrals, this may not have been such a concern.

There was no evidence in our data that first wave fundholders attempted to make budgetary savings by reducing referral rates. It is particularly noteworthy that outpatient referrals to the surgical specialties increased as outpatient referrals to these specialties are likely to lead to inpatient admissions for elective surgical procedures which could incur a substantial charge on the practice budget. ${ }^{9}$ This should be reassuring to those who feared that patients' access to specialist services would be curtailed as a result of the introduction of fundholding.

The fact that most practices' referral rates had increased in the second phase of the study provides no support for the view that first wave fundholders had artificially increased their rates of referral in the preparatory year to enable them to make budgetary savings in the subsequent year, although their rates were higher than those of the controls in phase 1 . There was some variation between the practices, but only three fundholders reduced their rates, which may be due to normal year on year differences. Of the two highest referring practices, only one reduced its referral rate and then only by a relatively small amount. Some of the control practices increased their referral rates quite dramatically in phase 2 . It is not clear why this happened, but it does illustrate the inherent instability in individual practices' annual referral rates and the consequent difficulties involved in estimating budgets on the basis of past referral patterns. ${ }^{6}$

Finally, fears that fundholders would encourage referrals to private clinics to avoid a charge on their budgets seem to be unfounded, certainly as far as these aggregate data are concerned, and there was only limited evidence that fundholders were making use of their freedom to contract with private hospitals for outpatient services for NHS patients.

\section{REASONS FOR LACK OF CHANGE}

What is the explanation for this apparent lack of effect? Part of the answer probably lies in the attempt to maintain a "steady state" in the first year of the reforms. General practitioners were enticed to join the fundholding scheme by the promise of new freedoms in their gatekeeping role, ${ }^{10}$ but when it became apparent that their potential to destabilise the system threatened other aspects of the reforms regional health authorities were told to "manage the market" to ensure that the stability of hospitals was not threatened. The Oxford Regional Health Authority introduced "the 80/20 rule," under which fundholders agreed to contract for $80 \%$ of their hospital services budget in the first year to go to the same hospitals as in the preparatory year, leaving them free to move the remaining $20 \%$ if they so wished. Very few practices exploited this freedom to the full. Some fundholders did switch hospitals for some specialties where they were promised a better or a 
cheaper service. These changes occurred particularly in diagnostic services, which were excluded from our analysis. Several practices were offered cheaper contracts by private hospitals for pathology and radiology services, but none of the study practices took this up.

Two practices used different provider units in phase 2 for individual specialties: in both cases this involved arranging for consultants from the new provider units (in orthopaedics and urology) to see patients on the practice premises. Others managed to negotiate favourable terms with their existing providers, thus achieving savings without affecting referral patterns. Some arranged for consultants to hold clinics on the practice premises, thus improving access for their patients but not necessarily achieving a cost saving. Others increased provision of minor surgery with a view to reducing referrals to certain specialties. Many hoped to achieve a reduction in numbers of follow up appointments. However, for the most part the fundholders' business plans indicated that they planned to make savings in the prescribing element of their budgets rather than in hospital services.

Another factor which may have been important in this first year of the reforms was the determination of these pioneering fundholders to ensure the success of the scheme. There is no doubt that they were sincere in their belief that their patients would benefit from their involvement. ${ }^{2}$ Many had faced hostility from colleagues who were opposed to fundholding. The government was also particularly anxious in an election year to ensure both that the benefits of the scheme were recognised and that accusations that they were encouraging the development of a two tier service were not substantiated. Thus it seems likely that health authorities were encouraged to be generous in the allocation of budgets, that fundholders were less concerned than they might otherwise have been about the need to stay within strict cash limits, and that nonfundholders were allowed greater freedom of referral than might have been anticipated.

\section{Conclusion}

The overall increase in referral rates may seem disappointing to those who hoped that fundholding would provide a mechanism for reducing the demand for specialist care, but it was probably unrealistic to expect a shift to occur in the first year of the scheme. Although we found no evidence that the referral behaviour of first wave fundholders was affected by budgetary pressures, this may not be indicative of the way in which the effects of the reforms will be felt in the next few years. It will be important to continue to monitor these effects.

We are very grateful to the general practitioners, their practice managers, and support staff, without whom this study would not have been possible. The study was funded by the Oxford Regional Health Authority.

1 Secretaries of State for Health, Wales, Northern Ireland, and Scotland. Working for patients. London: HMSO, 1989.

2 Glennerster H, Matsaganis M, Owens P. A foothold for fundholding. London: King's Fund Institute, 1992.

3 Bain J. Budget holding in Calverton: one year on. BMf 1992;304:971-3.

4 Roland M. Fundholding and cash limits in primary care: blight or blessing? BM7 1991;303:171-2.

5 Roland M, Coulter A, eds. Hospital referrals. Oxford: Oxford University Press, 1992.

6 Coulter A. Fundholding general practices. BMF 1992;304:397-8.

7 Bradlow J, Coulter A, Brooks P. Patrerns of referral. Oxford: University of Oxford Health Services Research Unit, 1992.

8 Gardner MJ, Altman DG. Statistics with confidence. London: British Medical Journal, 1990 .

9 Coulter A, Seagroatt V, McPherson K. Relation between general practices' outpatient referral rates and rates of elective admission to hospital. $B M$ 1990;301:273-6.

10 Department of Health. Funding general practice: the programme for the introduction of general practice budgets. London: Department of Health, 1989.

(Accepted 16 December 1992)

\section{Screen detected high blood pressure under 40: a general practice population followed up for 21 years}

Medical Research Council Epidemiology and Medical Care Unit, Northwick Park and Glyncorrwg Health Centre, West Glamorgan SA13 3BL

Julian Tudor Hart, general practitioner

Glyncorrwg Health Centre, West Glamorgan SA13 3BI Catherine Edwards, practice manager

Mary Hart, research team leader

Janet Jones, practice nurse Margaret Jones, practice nurse

University College London

Medical School

Andrew Haines, professor of

primary health care

Department of Public

Health, University of

Glasgow

Graham Watt, senior lecturer

Correspondence to:

DrJ T Hart.

BMF 1993;306:437-40

Julian Tudor Hart, Catherine Edwards, Mary Hart, Janet Jones, Margaret Jones, Andrew Haines, Graham Watt

\section{Abstract}

Objective-To assess hypertension detected under 40 in a general practice population.

Design-Prospective case-control study.

Setting and subjects-Former coal mining community in south Wales. Systematic case finding for hypertension and associated risk factors applied to a mean total population of 1945 from age 20 on a five year cycle through 21 years. Mean population aged 20-39, 227 men and 213 women. Case criteria: age $<40$ and mean systolic pressure $\geqslant 160 \mathrm{~mm} \mathrm{Hg}$ or diastolic pressure $\geqslant 100 \mathrm{~mm} \mathrm{Hg}$. Age and sex matched controls randomly sampled from the same population.

Main outcome measures-Mean initial pressures and pressures at follow up in 1989 or preceding death, and all cardiovascular events.

Results-25 men and 16 women met criteria. Estimated five yearly inceptions were $26 / 1000$ for men and 18/1000 for women. Male group mean initial blood pressure was $164 / 110 \mathrm{~mm} \mathrm{Hg}$ for cases, falling to $148 / 89 \mathrm{~mm} \mathrm{Hg}$ at follow up. Five male cases died at mean age $47 \cdot 8$, compared with two controls at 49.5. Female group mean initial pressure was
$172 / 107 \mathrm{~mm} \mathrm{Hg}$ for cases, falling to $145 / 86 \mathrm{~mm} \mathrm{Hg}$ at follow up. One female case died aged 50, no controls. 10 male cases had non-fatal cardiovascular events at mean age 40.2 , compared with two controls at mean age 50.5. Four female cases had non-fatal events at mean age 47.2, compared with one control aged 58 . Male differences were statistically significant.

Conclusions-Hypertension under 40 is dangerous, commoner in men than women, rarely secondary to classic causes, and may be controlled in general practice on a whole community basis.

\section{Introduction}

Primary hypertension usually begins early in life. Measurements are unstable and poorly predictive in adolescence, ${ }^{1}$ but from 20 years individual variability seems to be less and does not increase with age. ${ }^{2}$ Failure of antihypertensive treatment substantially to reduce coronary risk may partly be attributable to late intervention, after vascular changes are less easily reversible.

Measurement of blood pressure in young adults, though required by the new general practitioner contract every three years from April 1991, is still not 